\title{
Mario Faustino, Joaquim Cardozo e $o$ arquivo agora
}

Manoel Ricardo de Lima

Universidade Federal de Santa Catarina

RESUMO: O ARTIGO APRESENTA ALGO DO PROCEDIMENTO DE MÁRIO FAUSTINO COM A SUA PÁGINA DE CRÍTICA DE POESIA PUBLICADA NO SUPLEMENTO DOMINICAL DO JORNAL DO BRASIL, ENTRE OS ANOS DE 1956 E 1958, A PARTIR DE UMA IDÉIA DO ARQUIVO COMO AQUILO QUE SE DESCOLA DO USO SIMPLES DO COLECIONISMO. JUNTO A ESTA QUESTÃO, O CONCEITO MÓBIL DE JOAQUIM CARDOZO DA IMAGEM DO CRIVO E FORMA FORMANTE POSSIBILITA RELER A PROPOSIÇÃO ACERCA DO ARQUIVO.

ABSTRACT: THE ARTICLE SHOWS SOME OF THE PROCEDURE OF MÁRIO FAUSTINO WITH HIS PAGE OF POETRY'S CRITIC PUBLISHED ON THE SUNDAY SUPPLEMENT OF THE JORNAL DO BRASIL, AMONG THE YEARS 1956 AND 1958, FROM AN IDEA OF THE ARTICLE AS SOMETHING THAT GETS UNSTICK FROM THE SIMPLE USE OF COLLECTING. COMBINED WITH THIS QUESTION, JOAQUIM CARDOZO'S MOBILE CONCEPT OF THE SIEVE'S IMAGE AND OF THE FORMING FORM ENABLES TO READ AGAIN THE PROPOSITION ABOUT THE ARCHIVE.

PALAVRAS-CHAVE: PROCEDIMENTO, ARQUIVO, CRIVO, IMAGEM, POESIA KEYWORDS: PROCEDURE, ARCHIVE, SIEVE, IMAGE, POETRY 
ma idéia de leitura-presente em direção ao projeto de poema e crítica de Mário Faustino tem a ver com uma perspectiva empenhada: criar uma disposição para sair, um crivo para fora da história, alguma coisa próxima de uma ahistória; uma espécie de alargamento ou desarrumação que possa reler o seu arquivo agora. Uma prudência demorada, ou seja, pensar este projeto desfazendo a rigidez das leituras mais recentes que o tem deixado afásico em suas hierarquias, historicismos, categorizações e, principalmente, fixadas como leituras-críticas-cópias-mal-feitas-coladas-em-alguém. A tarefa agora, me parece, é tentar raspar minimamente uma leitura (ou releitura) de recuperação do projeto de Mário Faustino (1930-1962) como uma dança incerta, um traço desviante, generoso e aberto de sua poesia que desemboca em sua crítica. Esta última, como uma prática e um compromisso agarrados ao texto para jornal. Jornal que não é, senão, também, para Mário Faustino, um espaço de impasse, euforia e, principalmente, de pouco tempo.

Durante os anos de 1956 a 1958, Mário se dedicou a uma página no Suplemento Dominical do Jornal do Brasil, a que chamou de Poesia-Experiência. Nela, armou um arquivo que, sobremaneira, aponta para um outro lugar da coleção, como o que sugere Gayatri Spivak: não mais um simples colecionismo, mas uma operação que transcende a tradição problemática do colecionismo, ou seja, de deslocar seus usos. (SPIVAK, 1999, p. 205) E isto atravessa o pensamento de Mário Faustino numa idéia retirada de algo do Barroco na arte brasileira: "o movimento livre em lugar do equilíbrio fixo". Este movimento também comparece, como indicativo, por exemplo, no trabalho de Joaquim Cardozo entre o poema e a crítica de poesia, de arte e de arquitetura, mais ou menos no mesmo período da página de Mário, a partir daquilo que ele chama de a imagem do crivo. O crivo, a que se refere Joaquim Cardozo, e que também uso para ler Mário Faustino, é o que recupera a imagem de uma peneira, ou de um escoador; aquilo que vaza pelos furos. Um dos maiores impasses do poema e do pensamento crítico de Joaquim Cardozo é armar um ponto furo na imagem. E isto tem a ver diretamente com esta imagem do crivo, que é uma espécie de espaço informal, aberto, contingente, ou como ele prefere, uma forma formante. $\mathrm{O}$ crivo tem a ver também com o labirinto das rendas que são feitas no Agreste, em quase todo o Nordeste brasileiro, porque os principais fios usados na produção deste artesanato das rendeiras são provenientes do algodão, e as peças são feitas a partir do fio que é trançado no labirinto ou no 
crivo, o fio precisa vazar o tecido para ser visto. Com o tempo, as rendeiras que trabalham com o crivo, são acometidas de cegueira devido ao branco alucinatório do tecido e desse movimento repetitivo dos fios que escoam.

\section{Primeira digressão}

Joaquim Cardozo diz numa entrevista de 1971, comentando sobre as possibilidades gráficas de se compor um poema, que tinha feito alguns poemas que se desenhavam como árvores, árvores lógicas, tecidos, favos, crivos etc. Diz que partia de uma palavra, abria ramos nela e provocava a leitura da esquerda para a direita, de baixo para cima, da direita para a esquerda, de cima para baixo; diz também que isto era "um fenômeno a que já aludira, quando surgiu o Concretismo". Que, com isso, acreditava apresentar, então, "a possibilidade de se ler um poema como se vê uma pintura: não se pode vê-la toda de uma vez. Ela é percorrida pela vista e assim se pode seguir para a direita, para a esquerda, percorrê-la em todos os sentidos." Acrescenta dizendo que um poema pode ser feito assim, "usando-se árvore ou tecidos" e que "nos tecidos como nas árvores, a leitura não é linear. Há outras maneiras, como crivos ou grafos. Os grafos poderão ser como uma rede de linhas ligadas por pontos ou nós." O fato é que Joaquim Cardozo aponta para um devir do poema como uma preocupação a uma outra proposição do espaço, outra concepção de pensamento do espaço, através de uma idéia do crivo como um deserto, um deserto que se engendra no tempo. O crivo coloca em jogo o destino dos homens no mundo, pelo deserto. O deserto é então um espaço intensivo de distâncias e sem medidas, um Spatium intenso em vez de Extensio - como uma paisagem intima de afeções para interromper para interromper a história.

Antes, os moveres da página de Mário Faustino estão ligados a um plano extenso de Reynaldo Jardim que reuniu naquela década alguns nomes interessantes com a idéia de mudar os rumos do Suplemento e das maneiras que se praticava, até então, talvez, a crítica de poesia e de cultura que era feita no Jornal do Brasil naquele período. A página Poesia-Experiência se dividia em seções marcadas pela abrangência de acesso, como a "Poeta Novo", que apresentava os novos poetas junto a poetas conhecidos, a "Personae", que dava notícia das novidades poéticas no calor dos acontecimentos - entre publicações, autores etc -, e ainda outras seções como "O Melhor em Português", "Clássicos Vivos", "Fontes e correntes da poesia contemporânea", "É preciso conhecer" e "Evolução da poesia brasileira". 
O eixo de apresentação da coluna obedecia a uma forma didática e a um caráter quase instrumental de uma leitura crítica de muito da poesia moderna do ocidente, cumprindo um caráter pessoal de Mário Faustino, o seu gesto judicativo. Ao mesmo tempo, Mário Faustino procurava abrir este gesto para um movimento progressivo muito colado no princípio do conceito de "evolução". Era uma maneira de apresentar para um público leitor de jornal, um público feito por leitores comuns (ou seja, leitores não-especializados em poesia), uma mimese interna da literatura com apropriação e seleção de poetas e poemas num arquivo autoritário ao qual procurava atribuir uma variação de graus de importância. O arquivo é ordenado a partir e com algumas das premissas básicas das vanguardas críticas do século XX, premissas também retiradas de algumas de suas preferências poético-críticas, como Erza Pound e T.S. Eliot e o New Criticism; e, no Brasil, Jorge de Lima (poeta que mereceu notória atenção de Mário Faustino durante esses poucos anos em que durou a página). Neste sentido, Mário Faustino ampliava e aplicava no Brasil, talvez pela primeira vez, a idéia do poeta americano Ezra Pound de fazer o novo (tão cara às vanguardas e, depois, à poesia concreta brasileira, por exemplo). Ezra Pound chama a essa idéia, a esse procedimento, de make it new, uma proposição que tem a ver com fazer a própria seleção, com escolher (que desemboca na idéia do paideuma); tem a ver também com ponto de partida, com repetição, com renovação e inovação; e este procedimento passa a ser a pauta de Mário Faustino. Tanto que o lema da página era: "repetir para aprender, criar para renovar".

Na parte intitulada "Evolução da poesia brasileira", por exemplo, procura reler a poesia do Brasil colônia, como a de Bento Teixeira, de Antônio José da Silva, Botelho de Oliveira ou de Souza Caldas, entre outros, para provocar a partir dessas leituras um encontro com o presente, um encontro do presente com um "documento humano", entre progresso e retorno como ondulação e ciclo. Ao comentar sobre Souza Caldas, por exemplo, argumenta acerca da recuperação da poesia como um esforço, o de "dar à língua uma nova dimensão, seja em que sentido for - eis o que marca, antes de mais nada, a importância de um poeta." (FAUSTINO, 1993, p. 143) Esta marca que vem do mesmo problema tratado por T.S. Eliot num sem número de seus ensaios acerca do lugar e da função da poesia e do poeta. 


\section{Segunda digressão}

Para Joaquim Cardozo o "esforço" para a poesia vem do cálculo estrutural, seu ofício. Esforço tem a ver com uma espécie de teoria da deformação, porque no cálculo estrutural tudo é feito para que não se deforme nem deforme o "real" daquilo que constrói; para Joaquim Cardozo isto é um "estágio da experimentação em que o corpo se deformando começa a deformar, por sua vez, o corpo deformador." Dai, deste procedimento do esforço ele retira a sua idéia de "forma formante" e da "imagem do crivo".

Mais adiante, Mário Faustino volta a afirmar uma de suas inferências mais fortes sobre a poesia feita no Brasil, o de que ela só passou a ter cotejo com qualquer outra poesia do ocidente a partir do modernismo: "pois, nunca é demais repetir, a poesia brasileira - com duas ou três exceções - só atinge o nível internacional já em pleno século XX." (FAUSTINO, 1993, p. 143) Ainda, no mesmo trecho, chama atenção para a importância da tradução como tarefa crítica e poética, ao dizer coisas como: "é preciso deixar bem claro que pouquíssimas obras poéticas contemporâneas de Souza Caldas representam para a língua o que significam suas traduções (diretamente do hebraico) de inúmeros salmos da Bíblia." (FAUSTINO, 1993, p. 144) Sobre Botelho de Oliveira, também para exemplo, arrisca dizer que a sua importância é de fundação histórica, porque foi o primeiro poeta nascido no Brasil a ver impressas suas obras, o primeiro poeta brasileiro verdadeiramente "profissional", e não "boêmio" (os termos são piedosos), tendo na poesia o seu principal interesse; seria Botelho de Oliveira, assim, para Mário, o nosso primeiro verse maker de vulto.

Importante notar que a tarefa crítica de Mário Faustino aponta o tempo inteiro para sua preocupação de poeta, para sua tarefa como poeta, e é aqui que pode se constituir a mora, o crivo. Uma tarefa que ele procura cumprir no seu único livro de poemas - O Homem e sua Hora (1955) -, quando toma como pauta uma insistência em fazer o fragmento se mover para construir o poema longo; a obsessão de Mário Faustino é remexer e remover a tradição do poema longo até fazê-lo fragmento, porém ainda longo. O livro insiste nesta clave e numa deambulação, como já apontei: um encontro com o presente, um encontro do presente com um "documento humano", progresso e retorno como ondulação e ciclo. Algo como "corso e ricorso", para seguir a indicação de Giambattista Vico: corso e ricorso para entrar e sair da história, para fazer o poema se mover no presente, num tempo agora. 
Vico diz que é nesta proposição de movimento, corso e ricorso, que aparece o que chama de dignidade para a poesia. Que esta dignidade está diretamente vinculada a uma ética fundada pelo poema (de outra maneira, esta é a mesma inflexão usada por Konstantinos Kaváfis em suas Reflexões sobre Poesia e Ética: "Percebi claramente, certa tarde de janeiro de 1904, que eu deveria ter-me sentido mais à vontade, com uma vida mais plena, se tivesse podido lembrar uma manhã ou dia satisfatório para minha ânsia de uma foda; o que é prova da veracidade de "Um Velho"). (KAVAFIS, 1998, p. 61) e por Lezama Lima, em seu conhecido ensaio "A dignidade da Poesia", de 1956: "Mas do ponto de vista da criação, da poesia, o que nos atrai é a potência concorrente, a pureza primigênia do grito e do sorriso.(...) um grito que levanta o jorro das profundezas, ou como o sorriso que abranda uma fonte." (LIMA, 1996, p. 179)

Vico argumenta que esta relação entre dignidade e ética está numa evidência das imagens poéticas que o homem precisou construir desde a infância, como lugar de fantasia (il fanciullo); para ele a fantasia é uma memória, uma dilatação, uma compósita. E afirma que "Os homens primeiramente sentem sem se aperceberem, a seguir apercebem-se com o espírito perturbado e comovido, e finalmente, refletem com mente pura. Este aforismo é um princípio das sentenças poéticas, que são formadas com sentidos de paixões e de afetos." (VICO, 1979, p. 46). E complementa: "Os homens às coisas dúbias ou obscuras, que lhes dizem respeito, naturalmente as interpretam segundo as naturezas constitucionais das mesmas, ou seja, como resultantes de paixões e de costumes." (VICO, 1979, p. 46) O fato é que, para Vico, a história comparece como uma luta cósmica, entre paixões, costumes, coisas obscuras, dúvidas, e assim ela também comparece como aquilo que criamos para penetrá-la através da poesia, sem peias. E é aqui que Mário Faustino arma o vinco de seu procedimento poético-crítico, um procedimento cruzado, a partir de Vico: corso e ricorso.

É possível verificar isto, para exemplo, em um poema que se desdobra num plano de composição. O poema se intitula "A reconstrução" e faz parte de um conjunto disperso e provisório que é costumeiramente tomado sob a pecha de "primeiros poemas" ou de "últimos poemas" (e é fato que não se pode dizer que Mário teve uma produção da juventude ou da maturidade, tendo em vista a sua morte precoce, aos 31 anos num acidente aéreo. O que ele mesmo publicou está todo reunido num único e magro volume, O Homem e sua Hora, de 1955). Este é, a meu ver, um de seus poemas mais problemáticos entre 
longo e fragmento, o poema se espalha por sete páginas e escorre uma larva de morte enquanto persegue uma brecha para um movimento livre de criação e vida. Diz ele no trecho inicial do poema:

Em cinza de derrota nos deitamos

Abraçando sangrento camarada.

E acordamos desertos, um cadáver

Precoce em nossos abraços, a vitória

Lavrando noutro campo. Então lavamos

Esse alheio troféu para entregá-lo

Absterso à sua origem. Demarcamos

A cova com três pedras e saímos

Em busca de uma fonte para nós

Vivos, talvez, e tão sedentos. Éramos

Um só por entre as poças pantanosas

E os membros inconjuntos. (...)

(FAUSTINO, 1985, p. 99)

A anotação que aparece no plano de composição do poema, armando relações com Dante, Camões, a Bíblia, Confúcio, Sil Gawain, Diogo Cão e Fernão Lopes, é também o seu plano de reconstrução crítica e poética. A anotação diz: "fica a meu lado, (...), agora". E isto me parece gerar um arquivo em plena desincorporação e dessubjetivação. É possível aí ler o procedimento crítico de Mário Faustino como um modo de uso recorrente da colagem alucinada e a-histórica, do recorte que faz de trechos de textos críticos (assim como fazia Vico) e de poemas, tanto em português como em outras línguas, e os dispor na página seguindo a medida de seus interesses e intenções do gesto: a montagem aberta, colocar, pôr ao lado e, por que não, pôr de lado. Assim, a sua página, não à toa chamada de Poesia-Experiência, pode e deve ser lida nessa clave que vem da imagem de um crivo, também sugerida por ele e muito pouco percebida, que está armada como uma proposição crítica para a desincorporação literária, como uma política de leitura para uma dessubjetivação do arquivo. Com uma leitura do presente que pode sempre dizer de um arquivo por vir, um arquivo que tem como proposta uma outra política da memória, esta memória do presente, esta memória agora: "fica a meu lado, (...), agora". 
E por fim, importante dizer, como nota, que é parte desta leitura do trabalho de Mário Faustino abrir o olho cego ao que já está parcialmente organizado em livro, ou por Benedito Nunes ou por Maria Eugênia Boaventura ou por Albeniza de Carvalho e Chaves, tanto de sua poesia, quanto de sua crítica e de muito da sua biografia; mas, principalmente, que há outro mover-se sobre seu trabalho que prefere outras articulações menos impositivas do arquivo fixo, como os importantes trabalhos publicados mais recentemente: um de Carlos Evandro Martins Eulálio, chamado Mário Faustino em Curso, editado no Piauí pela editora Corisco, e um outro, de Lília Silvestre Chaves, chamado de Mário Faustino, uma biografia, editado pelo IAP, do Pará.

\section{Digressões finais: o crivo, a renga}

Vicente Cecim num fragmento de texto que se repete em seu livro $A$ Asa e A Serpente, publicado em 1979, quando o narrador avança sobre a sua personagem, o sargento Nazareno, morto, diz: "Meti a mão no passado, mas é um passado que guardo na cabeça sem ter vivido um só momento dele, eu não estive lá, repito, (...). Você tem esse olho cego, me perguntam, não está revoltado? Pisco para mim mesmo, enquanto avanço para apunhalar, desta vez em pleno peito, o morto adormecido na praça. Então, será assim. E devo matá-lo quantas vezes forem necessárias. Eu não esqueci, como os outros, e se agora ele nos quer outra vez de joelhos, devo recusar a humilhação pela adoração, como recusei a humilhação pelo medo. Matá-lo outra vez pela cabeça, outra vez pelas costas, outra vez pelos pés e por seus olhos que tentam essa luz inumana para nos submeter. É preciso não permitir que ele nos impeça de perseguir a felicidade. (...) Estamos prontos para recomeçar." (CECIM, 1979, p. 94)

Este sulco construído por esse ato de meter a mão no passado, armado pelo narrador de Cecim que mata a sua personagem morta ("um cadáver precoce em nossos abraços"), e que se reconfigura também como um crivo a partir desse olho cego que mata o morto e, principalmente, que não abre mão de perseguir a felicidade e recomeçar, é retirado do jogo rengado entre interrogativa, afirmativa e resposta da terceira e quarta estrofes de um poema de Mário Faustino, datado de 1952, que se intitula "No Trem, pelo Deserto". Poema que 
se desenha como um crivo, aberto, como uma luz inumana que apunhala outra vez o morto no deserto, sem adoração e sem medo. Diz o poema:

\section{No trem, pelo deserto}

As vozes frias

Anulam toda chance de existência.

Jogam cartas terríveis

Batem fotografias perigosas

Não temem. Falam. Passam,

$\mathrm{Na}$ chacina do raro ostentam sua miséria.

Ninguém veste de verde. Um só

Parece vivo, aberto - e esse dorme.

As aves lentas voam seus presságios

E a brisa morna engendra flores duras

$\mathrm{Na}$ secura dos cactos.

Alguém pergunta: “Estamos perto?” E estamos longe

E nem rastro de chuva. E nada pode

Salvar a tarde.

(Só se um milagre, um touro

Surgisse dentre os trilhos para enfrentar a fera

Se algo fértil enorme aqui brotasse

Se liberto quem dorme se acordasse).

(FAUSTINO, 1985, p. 193)

Numa continuação da renga, o poeta Max Martins, publica o seu primeiro livro, O Estranho, em 1952, sob o impacto da leitura do livro de poemas de Mário Faustino (ainda inédito), e das conversas com Robert Stock sobre este O Homem e sua Hora. Stock, por sua vez, era uma espécie de hippie avant la lettre, americano egresso da comunidade beat de Big Sur, na Califórnia, e que viveu em Belém durante três anos na companhia da esposa Henriette, uma filha ainda criança e um macaco, o Parsifal. Mário traduziu algo de sua poesia, e 
estes poemas foram publicados no n. 3, da revista Norte, editada por Benedito Nunes, o próprio Mário e Max Martins. No livro H'era, publicado em 1971, Max Martins continua, entre corso e ricorso, movendo a renga: antecipa a imagem do narrador de Cecim, a de apunhalar o peito do morto, e recupera a do trem-touro crivado do trabalho de Mário Faustino, para uma hora maiúscula, agora, que é a hora indiferente. Diz o poema:

\section{Negro e taciturno, o touro}

Negro e taciturno, o touro

outubro arqueja, e o seu sistema

se dissolve e não resolve

a questão de amar

e não amar

- que em suas virilhas ardem

dúvidas crepitantes - as doenças do mar - e feno duro.

E no entanto o noturno touro

desta tarde que invadiu meu sono,

persiste e não desiste

de pisar um peito

outrora palco e campo

de fúrias, melodramas, juventudes

(chão de ser tão ruim

e mágoas mal tratadas, rastros

que de seus olhos tristes se apagaram).

É um touro louco, babilônico, bêbado,

a ruminar os ímpetos

últimos

de sua carne-gosma

à Hora indiferente.

(MARTINS, 1992, p. 270) 


\section{Referências Bibliográficas}

FAUSTINO, Mário. Poesia - Experiência. São Paulo, Perspectiva, 1977. . Evolução da Poesia Brasileira. Salvador, Casa de Jorge Amado, 1993. - Poesia Completa Poesia Traduzida. São Paulo, Max Limonad, 1985. . O Homem e sua Hora e outros poemas. Organização de Maria Eugênia Boaventura. São Paulo, Cia das Letras, 2002.

CARDOZO, Joaquim. Entrevista, 1971, manuscrito.

CECIM, Vicente. A Asa e a Serpente. Belém, edição do autor/Semec, 1979.

CHAVES, Albeniza de Carvalho e. Tradição e Modernidade em Mário Faustino. Belém, UFPA, 1986.

EULÁLIO, Carlos Evandro Martins. A literatura pianiense em curso 2: Mário Faustino. Teresina, Corisco, 2000.

KAVÁFIS, Konstantinos. Reflexões sobre poesia e ética. Trad. José Paulo Paes. São Paulo, Ática, 1998.

LIMA, José Lezama. A dignidade da poesia. Trad. Josely Vianna Baptista. São Paulo, Ática, 1996.

LIMA, Manoel Ricardo de. Os sertões da espera, in Sibila - revista internacional de poesia e cultura. São Paulo: Ateliê Editorial, v.n. 02, p.72 - 76, 2002.

- A outra história e o nó. Fortaleza, Caderno Vida \& Arte, Jornal O POVO, em 12/08/2003.

. Por causa de Mário Faustino. Teresina, Caderno Dois, Jornal MEIO NORTE, em 02/05/1999.

MARTINS, Max. Não para consolar. Belém, Edições Cejup, 1992.

SPIVAK, Gayatri Chakravorty. A Critique of Postcolonial Reason. Cambridge, Harvard University Press, 1999.

VICO, Giambattista. Princípios de (uma) ciência nova (acerca da natureza comum das nações). Seleção, tradução e notas Antonio Lázaro de Almeida Prado. São Paulo, Abril Cultural, 1979. 